\title{
Regulation of Apolipoprotein A-1 and Apolipoprotein B100 Genes by Thymoquinone Rich Fraction and Thymoquinone in HEPG2 Cells.
}

\begin{abstract}
Thymoquinone (TQ) rich fraction (TQRF) extracted from Nigella sativa seeds using a supercritical fluid extraction technique was prepared. The regulatory effects of TQRF at 80 $\mu \mathrm{g} / \mathrm{mL}$ and commercial TQ at $2 \mu \mathrm{g} / \mathrm{mL}$ on apolipoprotein B100 (Apo B100) and apolipoprotein A-1 (Apo A-1) genes in the presence or absence of 25-hydroxycholesterol $(25 \mathrm{OH})$, were investigated in human HepG2 cell line using quantitative real-time polymerase chain reaction. Incubating HepG2 cells in 10\% human lipoprotein deficient serum (HLPDS) for $24 \mathrm{~h}$ in the presence of $2 \mu \mathrm{g} / \mathrm{mL} 25 \mathrm{OH}$ showed a significant increase in Apo B100 mRNA expression level by twofold compared to the control cells; on the other hand, no significant change in Apo A-1 mRNA level was observed. When cells were incubated with HLPDS in the absence of $25 \mathrm{OH}$ and treated with TQRF and TQ, the mRNA level of Apo B100 was down-regulated by 70 and 49\%, respectively, in TQRF and TQ treated cells compared to untreated cells. Apo A-1 gene was up-regulated by four- and twofold in TQRF and TQ treated cells, respectively, compared to that observed in untreated cells. The present study clearly shows that TQRF and TQ are effective in regulating Apo A-1 and Apo B100 genes that influence cholesterol metabolism in HepG2 cells.
\end{abstract}

Keyword: Apoliprotein A-1 genes; Apoliprotein B100 Genes; Thymoquinone (TQ); Nigella Sativa Seeds; Supercritical fluid extraction; Human; HepG2 cell line. 